\title{
Oncogene MYC
}

National Cancer Institute

\section{Source}

National Cancer Institute. Oncogene MYC. NCI Thesaurus. Code C17464.

A viral and cellular gene. A proto-oncogene, identified in several avian tumors, encoding a nuclear protein with a leucine zipper motif. 